\title{
N-Acetylcysteine Inhibits Ventilation-Induced Collagen Accumulation in the Rat Lung
}

\author{
Chuanxi Chen, ${ }^{1}$ Xiangdong Guan, ${ }^{1}$ Deborah A. Quinnn ${ }^{2}$ and Bin Ouyang ${ }^{1}$ \\ ${ }^{1}$ Department of Critical Care Medicine, The First Affiliated Hospital of Sun Yat-Sen University, Guangzhou, \\ Guangdong, P.R. China \\ ${ }^{2}$ Pulmonary and Critical Care Unit, Department of Medicine, Massachusetts General Hospital, and Harvard \\ Medical School, Boston, MA, USA
}

\begin{abstract}
Mechanical ventilation is the most important life supportive therapy for patients with acute respiratory distress syndrome (ARDS). However, increasing evidence from clinical studies suggests that mechanical ventilation can cause lung fibrosis, which may significantly contribute to morbidity and mortality. Recent studies also found fibroproliferation occurred in early stage of ARDS with poor outcome. We have hypothesized that mechanical ventilation-induced lung injury may be a major contributor to lung fibrosis, and antioxidant could be a potential therapeutic agent for the treatment to mechanic ventilation induced fibroproliferation. We therefore used Sprague-Dawley rats that were ventilated with large tidal volume (20 $\mathrm{ml} / \mathrm{kg}$ ) or low tidal volume $(7 \mathrm{ml} / \mathrm{kg})$. We analyzed the time course of collagen level in the lung and the effect of $\mathrm{N}$-acetylcysteine (NAC), a thiol antioxidant, on mechanical ventilation-induced collagen accumulation. In addition, normal human lung fibroblasts (NHLF) were exposed to mechanical stretch, which mimics ventilator-induced lung inflation, to evaluate the collagen secretion in culture medium. We found that ventilation-induced collagen accumulation occurred even after 2-hour ventilation. Pretreatment with NAC $(140 \mathrm{mg} / \mathrm{kg})$ inhibited collagen accumulation in lungs of rats ventilated with large tidal volume. Moreover, mechanical stretch caused the accumulation of collagen in the culture medium of NHLF, the magnitude of which was decreased with the pretreatment with NAC $(1 \mathrm{mM})$. These results indicate that mechanical ventilation can induce collagen accumulation within 2 hours. NAC alleviated the collagen accumulation induced by mechanical ventilation with high tidal volume. Therefore, NAC can be considered as a good candidate in preventing ventilation-induced lung fibrosis.
\end{abstract}

Keywords: antioxidant; collagen; mechanical ventilation; $\mathrm{N}$-acetylcysteine; pulmonary fibrosis Tohoku J. Exp. Med., 2015 August, 236 (4), 255-261. C 2015 Tohoku University Medical Press

\section{Introduction}

Mechanical ventilation (MV), as a critical therapeutic strategy, has been widely used in clinical setting to provide adequate oxygenation to vital organs of patients with acute respiratory distress syndrome (ARDS). However, improper operation of mechanical ventilation would lead to a series of complications including ventilator-induced lung injury (VILI) which is characterized as inflammatory cytokines release, neutrophils influx and thus resulting in pulmonary edema formation (Slutsky and Ranieri 2013). Furthermore, mechanical ventilation has been reported to be associated with pulmonary fibrosis as it is revealed that $53 \%$ of ARDS patients who received mechanical ventilation for $\geq 5$ days had been found to develop pulmonary fibrosis (Papazian et al. 2007). Pulmonary fibrosis worsens lung compliance and oxygenation. It has been documented in a prospective cohort study that ventilated ARDS patients who have devel- oped pulmonary fibrosis exhibited higher mortality (57\%) compared to patients without evidence of fibrosis (Martin et al. 1995).

As a pathogenic response in ARDS patients, fibroproliferation is characterized by fibroblast accumulation, collagen and other extracellular matrix (ECM) components deposition, which results in lung remodeling, and ultimately leading to lung fibrosis (Burnham et al. 2014). However, the factors that determine fibroproliferative development in ARDS patients and the cellular mechanisms responsible for this pathogenic response are poorly understood. Increasing evidence from clinical studies suggested that VILI may be a major contributor to the development of lung fibrosis in ARDS (Cabrera-Benitez et al. 2014). Airway stretch caused by mechanical ventilation resulted in an enhanced type III procollagen (PCIII, a byproduct of type III collagen synthesis) gene expression (Parker et al. 1997; Garcia et al. 2004), which further led to an increased expression of fibro-

Received March 24, 2015; revised and accepted June 18, 2015. Published online July 8, 2015; doi: 10.1620/tjem.236.255.

Correspondence: Bin Ouyang, Department of Critical Care Medicine, The First Affiliated Hospital of Sun Yat-Sen University,

No. 58 Zhongshan Er Lu, Guangzhou, Guangdong, 510080, P.R. China.

e-mail: binouyang@yahoo.com 
nectin (a fibroblast growth factor) and transforming growth factor $\beta 1$ (TGF- $\beta 1$ ) genes (Tatler and Jenkins 2012). Meanwhile, mechanical stress also induced EpithelialMesenchymal Transition (EMT) (Cabrera-Benitez et al. 2012). These findings all suggest that mechanical ventilation can lead to pulmonary fibroproliferative responses. Unlike previous understanding, there is clear evidence of fibroproliferative responses such as increased synthesis of lung collagen, which leads to lung repair and fibrosis (Suki et al. 2005), in the earliest stages of ARDS and its correlation with a poor outcome (Marshall et al. 2000; Ichikado et al. 2012). Hence, mechanical ventilation may have contributed to the early collagen synthesis during the course of ARDS.

Moreover, mechanical ventilation induced neutrophil infiltration and oxidative stress, both of which may contribute to the development of pulmonary fibrosis ( $\mathrm{Li}$ et al. 2012a; Pires et al. 2012). Oxidants have also been suggested to facilitate the fibrotic response in the lung (Park et al. 2009). Hence, antioxidant could be a potential therapeutic agent for treating mechanic ventilation-induced fibroproliferation and for preventing lung fibrosis in ARDS patients. Meanwhile, N-acetylcysteine (NAC), a thiol antioxidant, has been reported to alleviate bleomycin-induced pulmonary fibrosis in rats ( $\mathrm{Li}$ et al. 2012b). Our previous study also demonstrated that NAC inhibited lipopolysaccharide (LPS)-induced oxidant injury and collagen synthesis in human embryonic lung fibroblasts (HELF) (Li et al. 2011).

In the present study, we aimed to address these important issues by using both in vivo and in vitro models to investigate mechanical ventilation-induced pulmonary fibroproliferation and the therapeutic effect of NAC on the mechanical ventilation-induced pulmonary fibroproliferation.

\section{Materials and Methods}

\section{Rat ventilation}

Animal study was approved by the Massachusetts General Hospital Subcommittee on Research Animal Care and conducted in compliance with guidelines of United States Department of Agriculture Animal Welfare Act, Public Health Service Policy on Humane Care and Use of Laboratory Animals.

Male Sprague-Dawley viral-free rats (180-230 g) were obtained from Charles River Laboratories (Wilmington, MA). Rats were anesthetized with intraperitoneal ketamine $(50 \mathrm{mg} / \mathrm{kg})$ and diazepam (5 $\mathrm{mg} / \mathrm{kg}$ ). After performing oral intubation was with a $2.42 \mathrm{~mm}$ OD (1.67 ID) polyethylene catheter, rats were randomly assigned to one of three groups: tidal-volume of $7 \mathrm{ml} / \mathrm{kg}\left(\mathrm{V}_{\mathrm{T}} 7 \mathrm{ml} / \mathrm{kg}\right)$, tidal-volume of $20 \mathrm{ml} / \mathrm{kg}\left(\mathrm{V}_{\mathrm{T}} 20 \mathrm{ml} / \mathrm{kg}\right)$ and without mechanical ventilation on room air as control. The dose was chosen based on previous studies (Quinn et al. 2002; Mascarenhas et al. 2004; Syrkina et al. 2008).

Rats were ventilated at 85 breaths/minute for 2,4 , or 6 hours on room air. During ventilation the arterial $\mathrm{pH}$ was maintained at 7.3 7.45 and $\mathrm{PaCO}_{2}$ was maintained at $30 \sim 40 \mathrm{mmHg}$ by increasing the amount of dead space. Cardiac output and mean carotid artery pressure were maintained at a stable level as previously described
(Choi et al. 2003). After ventilation rats were allowed to recover from anesthesia and extubated. At 2 hours after ending ventilation, rats ( $n=6 /$ group) were anesthetized again and euthanized, lungs were harvested en bloc for collagen assay.

To explore collagen accumulation after the end of mechanical ventilation, rats were ventilated for only 2 hours. At 2, 24, 48, or 72 hours after the 2-hour ventilation, rats $(n=6$ /group) were anesthetized again and euthanized and lungs were harvested en bloc for collagen assay, At 24 hours after the end of ventilation, the rest of the rats ( $n=6$ /group) were euthanized. The left lungs were harvested and fixed for trichrome collagen staining.

\section{Cell culture and cell stretch}

Normal human lung fibroblasts (NHLF, Clonectics, San Diego, CA) were grown in Fibroblast Growth Medium (FGM; Clonetics, San Diego, CA) with 2\% Fetal-III serum (Hyclone, Logan, UT). NHLF were fed with $2 \mathrm{ml} / \mathrm{cm}^{2}$ of fresh media every two days and maintained in a humidified incubator with $95 \%$ air and $5 \% \mathrm{CO}_{2}$ at $37^{\circ} \mathrm{C}$.

Two days prior to stretching, cells were seeded in dishes with a density of $3 \times 10^{6} /$ dish. The dishes had a silicone elastic membrane bottom, which served as a stretchable cell-culture surface for use in the mechanical strain device. The silicone membrane was coated with fibronectin for NHLF. Two hours before stretching, cells were washed with $10 \mathrm{ml}$ of Hank's balanced salt solution (HBSS) twice and replaced with serum-free media. To mimic the overextension of lung cells in VILI, cells were placed on a mechanic deformation device (Martha Gray, US Patent 5348879, Massachusetts Institute of Technology, Cambridge, MA) as previously described (Dunn and Pugin 1999). Cells were stretched at 20 cycles/minute of $15 \%$ strain, which means $15 \%$ change in cell length to resting cell length and is associated with an approximately equaled lung stretch to $62 \%$ total lung capacity (TLC) (Karadag et al. 2004). Cells were subjected to 20 cycles/min of $15 \%$ strain for $0.5 \mathrm{~h}, 1 \mathrm{~h}$ and $4 \mathrm{~h}$. Parallel dishes of cells were seeded and grown in the same condition and maintained without stretch as control. The experiments were performed in 5\% $\mathrm{CO}_{2}$ at $37^{\circ} \mathrm{C}$. Cultured media were harvested 2 hours after stretch to allow time for protein production. Collagen level was then measured in each cultured medium.

\section{$N$-acetylcysteine administration}

To investigate the effect of NAC on the collagen accumulation, NAC, a thiol antioxidant (St. Louis, MO, USA) was tested in vivo and vitro experiment.

In vivo, NAC (140 mg/kg) (Syrkina et al. 2008) was administrated to rats ( $n=6 /$ group) by intravenous injection before ventilation with either $\mathrm{V}_{\mathrm{T}} 7 \mathrm{ml} / \mathrm{kg}$ or $\mathrm{V}_{\mathrm{T}} 20 \mathrm{ml} / \mathrm{kg}$, while the vehicle of $\mathrm{NAC}$, physiological saline was also injected to other rats $(n=6 /$ group $)$ before ventilation with either $\mathrm{V}_{\mathrm{T}} 7 \mathrm{ml} / \mathrm{kg}$ or $\mathrm{V}_{\mathrm{T}} 20 \mathrm{ml} / \mathrm{kg}$ as compared. At 2 hours after the 2-hour ventilation, the rats were euthanized. The right lung was harvested for collagen assay. Bronchoalveolar lavage (BAL) fluid was also measured for collagen level.

In vitro, static or stretched NHLF were incubated with or without NAC (1 mM) (Jafari et al. 2004) for 2 hours, and after a period of 2 hours, cell cultured media were harvested for measurement of collagen level.

\section{Collagen assay}

Collagen was quantified in the lung tissue and BAL from rats and cultured medium from NHLF with Sircol Collagen Assay kit 
(Accurate Chemical \& Scientific Corporation, Westbury, NY). The Sircol Assay is a dye-binding method designed for the analysis of acid and pepsin-soluble collagens. The kit is suitable for monitoring collagen produced in situ or during in-vitro cell culture and in-vitro ECM formation, detection limit is $1.0 \mu \mathrm{g}$ collagen. Sircol assays in lung tissues were confirmed with immunohistochemical staining with Toulouse-Lautrec 1-step trichrome stain kit (Biocare Medical, Walnut Creek, CA) (Lopez et al. 2006). Trichrome collagen staining was used to illustrate the distribution of collagen accumulation in the lung. Lungs were harvested at 24 hours after the 2-hour ventilation and fixed with $10 \%$ phosphate-buffered formalin, embedded in paraffin and cut in $10 \mu \mathrm{m}$ sections. Toulouse-Lautrec 1-step trichrome stain kit (Biocare Medical, Walnut Creek, CA) was used for the trichrome collagen staining.

\section{Statistical analysis}

All the data are expressed as means \pm standard error of the mean (SEM). Data were analyzed with Statview 4.5 (Abacus Concepts, SAS Institute, Cary, NC). ANOVA was used to assess the statistical significance of the differences followed by multiple comparisons with a Scheffe's test. Kruskal Wallis, a non-parametric test, was used to confirm ANOVA results in data that was not normally distributed. A $P$ value $<0.05$ was considered statistically significant.

\section{Results}

Collagen accumulated in lung tissue of rats exposed to high tidal volume ventilation

To investigate ventilation-induced pulmonary fibroproliferation, we examined lung collagen, a key component of pulmonary fibrotic lesions, in rats exposed to mechanical ventilation with different tidal volumes. The lung collagen content significantly increased in a time-dependent manner in rats ventilated with higher tidal volume $\left(\mathrm{V}_{\mathrm{T}} 20 \mathrm{ml} / \mathrm{kg}\right)$, compared to that in rats with low tidal volume $\left(\mathrm{V}_{\mathrm{T}} 7 \mathrm{ml} / \mathrm{kg}\right)$ (Fig. 1). Furthermore, when compared with control group without mechanical ventilation, low tidal volume $\left(\mathrm{V}_{\mathrm{T}} 7 \mathrm{ml} /\right.$ $\mathrm{kg}$ ) also increased total lung collagen contents at 4 and 6 hours.

To explore collagen accumulation after the termination of mechanical ventilation, we also measured lung collagen after only a 2 hour ventilation but harvested in different time points. In the high tidal-volume ventilation group $\left(\mathrm{V}_{\mathrm{T}}\right.$ $20 \mathrm{ml} / \mathrm{kg}$ ), total lung collagen was increased at 2 hours after ventilation, continued to rise at 24 hours, reached a plateau at 48 hours, and was no longer significantly elevated at 72 hours after ventilation. In low tidal-volume ventilation group $\left(\mathrm{V}_{\mathrm{T}} 7 \mathrm{ml} / \mathrm{kg}\right)$, collagen accumulation was significantly lower than that in high tidal-volume ventilation group but still increased at 24 and 48 hours compared with the non-MV control group (Fig. 2A).

We also performed trichrome staining to confirm collagen accumulation in lung tissue at 24 hours after ventilation. Intensive collagen accumulation was observed by trichrome stain in the injured lung areas in high tidal-volume ventilation group $\left(\mathrm{V}_{\mathrm{T}} 20 \mathrm{ml} / \mathrm{kg}\right.$ ) (Fig. 2B) as compared to low tidal-volume ventilation group $\left(\mathrm{V}_{\mathrm{T}} 7 \mathrm{ml} / \mathrm{kg}\right)$ (Fig. $\left.2 \mathrm{C}\right)$.

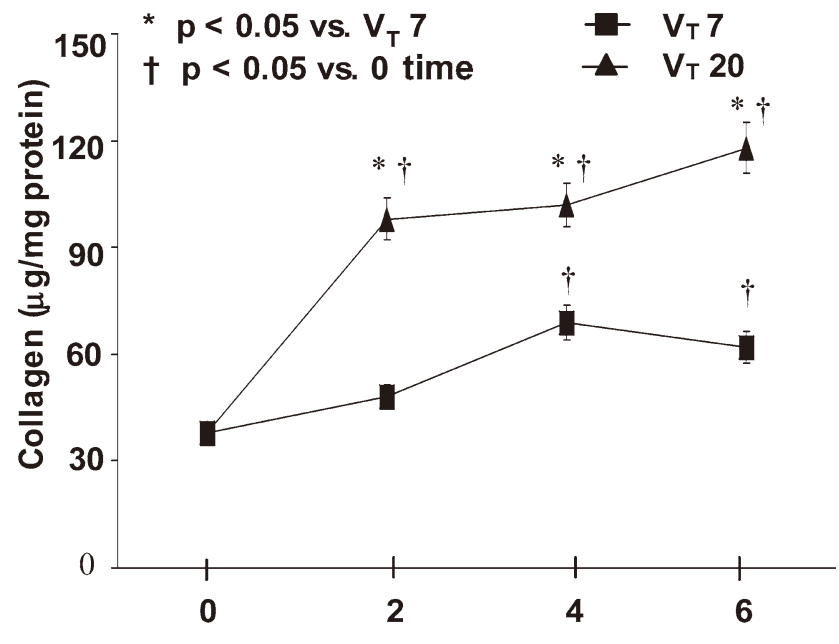

Hours of Mechanical Ventilation

Fig. 1. Total lung collagen content increases in rat lung tissue exposed to high tidal-volume ventilation.

Rats ( $\mathrm{n}=6$ /group) were ventilated at $\mathrm{V}_{\mathrm{T}} 20 \mathrm{ml} / \mathrm{kg}$ or $\mathrm{V}_{T} 7$ $\mathrm{ml} / \mathrm{kg}$ for 0 to 6 hours. In control group, rats were intubated without ventilation. Lung tissues were harvested at the end of 2 hours of ventilation. $* P<0.05$ vs. $\mathrm{V}_{\mathrm{T}} 7 \mathrm{ml} /$ kg. ${ }^{\dagger} P<0.05$ vs. 0 time.

$N A C$ intervention alleviates the collagen accumulation induced by high tidal-volume ventilation

To study the effects of NAC on collagen accumulation in rats exposed to high tidal volume ventilation, total lung collagen levels were measured. Increases of collagen were assessed in both lung tissue and BAL of rats subjected to $V_{T}$ $20 \mathrm{ml} / \mathrm{kg}$ compared with rats subjected to $\mathrm{V}_{\mathrm{T}} 7 \mathrm{~mL} / \mathrm{kg}$ for 2 hours (tissue: $\mathrm{V}_{\mathrm{T}} 7 \mathrm{ml} / \mathrm{kg}=47.25 \pm 1.73 \mu \mathrm{g} / \mathrm{mg}$ vs. $\mathrm{V}_{\mathrm{T}} 20$ $\mathrm{ml} / \mathrm{kg}=92.74 \pm 8.21 \mu \mathrm{g} / \mathrm{mg}, P<0.05$; and BAL: $\mathrm{V}_{\mathrm{T}} 7 \mathrm{ml} /$ $\mathrm{kg}=9.59 \pm 1.06 \mu \mathrm{g} / \mathrm{ml}$ vs. $\mathrm{V}_{\mathrm{T}} 20 \mathrm{ml} / \mathrm{kg}=28.14 \pm 5.43 \mu \mathrm{g} /$ $\mathrm{ml}, P<0.05)$. NAC intervention resulted in alleviation of collagen increases in both lung tissues and BAL fluids of rats subjected to $\mathrm{V}_{\mathrm{T}} 20 \mathrm{ml} / \mathrm{kg}$ for 2 hours (tissue: $\mathrm{V}_{\mathrm{T}} 20 \mathrm{ml} /$ $\mathrm{kg}=92.74 \pm 8.21 \mu \mathrm{g} / \mathrm{mg}$ vs. $\mathrm{V}_{\mathrm{T}} 20 \mathrm{ml} / \mathrm{kg}+\mathrm{NAC}=65.67 \pm$ $1.87 \mu \mathrm{g} / \mathrm{mg}, P<0.05$; and BAL: $\mathrm{V}_{\mathrm{T}} 20 \mathrm{ml} / \mathrm{kg}=28.14 \pm 5.43$ $\mu \mathrm{g} / \mathrm{ml}$ vs. $\mathrm{V}_{\mathrm{T}} 20 \mathrm{ml} / \mathrm{kg}+\mathrm{NAC}=12.18 \pm 0.75 \mu \mathrm{g} / \mathrm{ml}, P<$ $0.05)$, suggesting the inhibitory effect of NAC on collagen accumulation exposed to high tidal-volume ventilation (Fig. 3A, B).

Cyclic cell stretch induces early collagen secretion in NHLF

To study the contribution of cyclic cell stretch to collagen secretion in lung fibroblasts, we measured the collagen level in fibroblast culture medium after $15 \%$ cyclic strain for $0.5,1$ or 4 hours. A time-dependent increase in collagen level was documented that started after 1 hour and further elevated at 4 hours as compared to the control without stretch (Fig. 4A), suggesting cyclic cell stretch caused fibroproliferative responses in NHLF. 



Fig. 2. Collagen continues to increase in rat lung tissues after exposing to high tidal-volume ventilation.

Rats ( $\mathrm{n}=6$ /group) were ventilated at $\mathrm{V}_{\mathrm{T}} 20 \mathrm{ml} / \mathrm{kg}$ or $\mathrm{V}_{\mathrm{T}} 7$ $\mathrm{ml} / \mathrm{kg}$ for 2 hours. Lung tissues were harvested at the end of 2 hours of ventilation, and 24, 48 and 72 hours post ventilation respectively (A). ${ }^{*} P<0.05 \mathrm{vs}$. $\mathrm{V}_{\mathrm{T}} 7 \mathrm{ml} /$ kg. ${ }^{\dagger} P<0.05$ vs. Non-MV. The lungs, which harvested at 24 hours post-ventilation, were fixed with $10 \%$ formaldehyde buffer and stained with trichrome staining $\left(\mathrm{B}, \mathrm{V}_{\mathrm{T}}\right.$ $7 \mathrm{ml} / \mathrm{kg} ; \mathrm{C}, \mathrm{V}_{\mathrm{T}} 20 \mathrm{ml} / \mathrm{kg}$ ). The blue staining represents collagen accumulation. The magnifications are $100 \times$, and $400 \times$ in the inserts.

NAC decreases collagen content in cell culture medium induced by mechanical stretch in NHLF

Due to the important role of NAC in antioxidant defense, we examined whether NAC was involved in the process of cyclic cell stretch-induced collagen secretion in
A

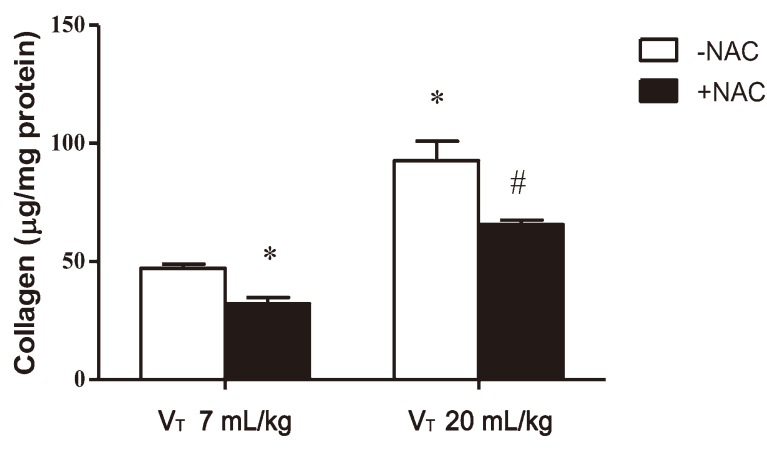

B

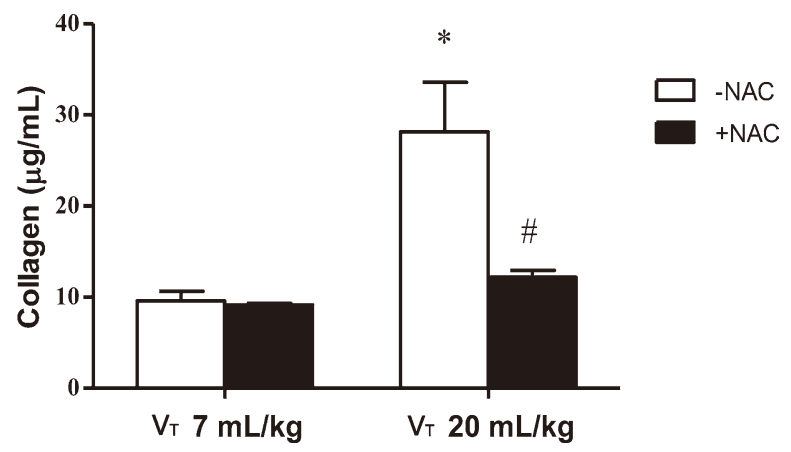

Fig. 3. N-acetylcysteine decreases total lung collagen in rats exposed to high tidal-volume ventilation.

$\mathrm{V}_{\mathrm{T}} 20 \mathrm{~mL} / \mathrm{kg}$ for $2 \mathrm{~h}$, followed by a $2 \mathrm{~h}$ recovery period, significantly increased the collagen level in lung tissue (A) and in BAL fluid (B) as compared to rats ventilated at $\mathrm{V}_{\mathrm{T}} 7 \mathrm{~mL} / \mathrm{kg}$. Pretreatment with NAC alleviated the collagen increases in both lung tissue and BAL fluid. ${ }^{*} P$ $<0.05$ vs. $\mathrm{V}_{\mathrm{T}} 7 \mathrm{~mL} / \mathrm{kg}$. ${ }^{\#} P<0.05$ vs. $\mathrm{V}_{\mathrm{T}} 20 \mathrm{~mL} / \mathrm{kg}$.

NHLF. The results showed that cyclic cell stretch in NHLF cells for 2 hours significantly increased collagen level in culture medium compared with static controls (Control: $21.54 \pm 8.02 \mu \mathrm{g} / \mathrm{ml}$ vs. stretch: $43.42 \pm 9.49 \mu \mathrm{g} / \mathrm{ml}, P<$ 0.05). In NAC pre-incubated NHLF, the stretch-induced collagen accumulation in the culture medium was significantly decreased (stretch: $43.42 \pm 9.49 \mu \mathrm{g} / \mathrm{ml}$ vs. stretch with NAC: $16.69 \pm 4.6 \mu \mathrm{g} / \mathrm{ml}, P<0.05)$. These data suggest that NAC can inhibit the fibroproliferative response included by cyclic cell stretch (Fig. 4B).

\section{Discussion}

Lung fibrosis was traditionally considered as a late event in ARDS, but several studies have demonstrated fibrotic change can occur in the earliest stages of ARDS. The concentration of PC III, a byproduct of type III collagen synthesis is higher in serum and lung lavage fluids in ARDS patients compared with control patients at $24 \mathrm{~h}$ (Marshall et al. 2000), and 47\% of patients had evidence of fibroproliferation assessed by high-resolution computed tomography (HRCT) on the first day of ARDS (Ichikado et al. 2012). The elevated level of PC III and pulmonary fibroproliferation in early ARDS are predictive of increased mortality and poor outcome (Chesnutt et al. 1997; Marshall 


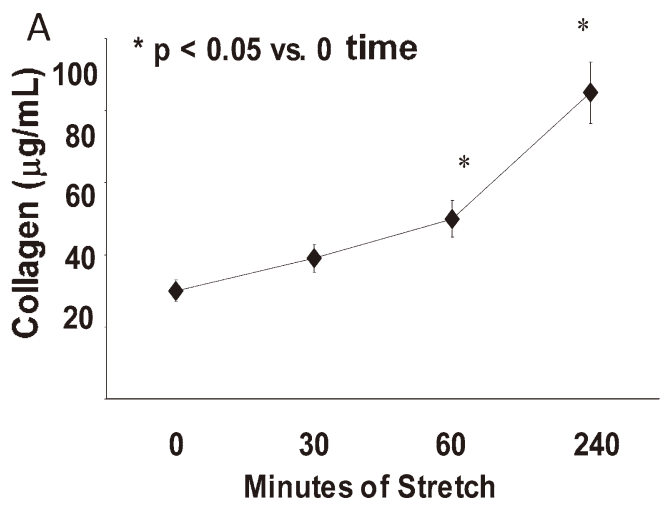

B

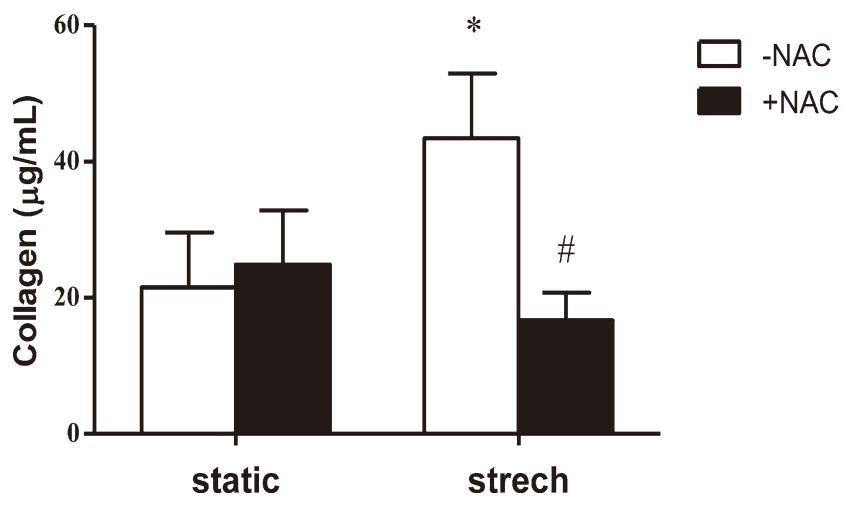

Fig. 4. Collagen accumulation in culture media of NHLF exposed to cyclic stretch and the effect of NAC on collagen accumulation.

(A) NHLF cells were exposed to cyclic stretch for $0.5,1$ and 4 hours ( $n=6$ /group). Cell culture medium was harvested 2 hours after stretch for measurement of collagen level. $* P<0.05$ vs. static. (B) Cyclic stretch for 2 hours significantly increased the collagen level in cell culture medium. Pretreatment with NAC decreased collagen content in culture medium of NHLF exposed to the cyclic stretch. ${ }^{*} P<0.05$ vs. static. ${ }^{\#} P<0.05$ vs. stretch.

et al. 2000; Ichikado et al. 2012). The early application of mechanical ventilation may have altered collagen synthesis early in the course of ARDS (Cabrera-Benitez et al. 2014). A study of an acid-induced lung injury model in mice revealed that the 2-hour mechanical stretch induced lung fibrosis formation (Cabrera-Benitez et al. 2012). Another study demonstrated that pulmonary fibrotic changes were induced at the early stage by mechanical ventilation in lungs without preexistent lung disease (Villar et al. 2011). Here, we showed that the mechanical ventilation for 4 hours with high tidal volume $(20 \mathrm{ml} / \mathrm{kg})$ caused marked collagen deposition in rats.

In our in vivo study, we found that high tidal volume ventilation $(20 \mathrm{ml} / \mathrm{kg})$ induced lung collagen accumulation, which started after the 2-hour ventilation in rats. Even low tidal-volume ventilation $(7 \mathrm{ml} / \mathrm{kg})$ also mediated collagen accumulation after the 4-hour ventilation. These results indicate that collagen accumulation occurs rapidly after mechanical ventilation. Furthermore, we found collagen accumulation continued to rise after the 2-hour ventilation, which was obvious in high tidal-volume group. Even in low tidal-volume group, collagen accumulation increased significantly at 24 and 48 hours after the 2-hour ventilation compared with the non-MV control group. In our in vitro study, NHLF were used to investigate the secretion of collagen because fibroblasts are the major source of collagen. The stretch-induced collagen level increased in culture medium which started as early as after 1 hour after stretch of NHLF. These results support that mechanical ventilation plays a critical role in early collagen accumulation. Interestingly our study found low tidal-volume mechanical ventilation $(7 \mathrm{ml} / \mathrm{kg}$ ) could also increase collagen level in lung tissues, because the low tidal-volume mechanical ventilation is also positive pressure ventilation. When compared with high tidal-volume mechanical ventilation, it can indeed cause less injury to lung. However, when the lung was exposed to low tidal-volume mechanical ventilation for a relatively long time, it can induce significant collagen deposition compared with non-ventilation group. In clinical setting, to avoid the positive ventilation-induced lung injury no matter high or low tidal volume, once the function of respiration is restored, it is suggested to extubate as soon as possible.

Mechanical stretch has been previously associated with superoxide production and oxidative stress. Superoxide $\left(\mathrm{O}_{2}^{-}\right)$production increased significantly after cyclic mechanical stretch of 2 hours in pulmonary epithelial cells (Chapman et al. 2005). Significant increases in reactive oxygen species (ROS) were also measured in type I-like rat alveolar epithelial cells after 10-minute cyclic stretch at $37 \%$ change in surface area (Davidovich et al. 2013), and increased ROS production was dependent on the time and magnitude of stretch. We also found that high tidal-volume ventilation could cause a decline in lung glutathione (GSH) content and a rise in the levels of serum isoprostane in the same rat model (Syrkina et al. 2008).

The oxidative stress is a potent stimulus for the production of TGF- $\beta$ that seems to enhance the fibrotic response in the lungs (Park et al. 2009). Imbalance between oxidant production and antioxidant protection results in accumulation of ROS oxidants may contribute to the development of pulmonary fibrosis due to their effects on the production of TGF- $\beta$ ( $\mathrm{Li}$ et al. 2013), suggesting that using antioxidants may be helpful in the prevention, and perhaps the treatment of fibrosis in VILI.

NAC is now clinically available as an antioxidant using in patients with idiopathic pulmonary fibrosis (Raghu et al. 2011). We therefore investigated whether NAC could also alleviate lung collagen accumulation in VILI. NAC was first found as a thiol antioxidant and has the potential to produce GSH. It can increase plasma GSH levels in a dose-dependent manner (Bridgeman et al. 1994). NAC also increased intracellular GSH concentrations in alveolar mac- 
rophages and inhibits $\mathrm{H}_{2} \mathrm{O}_{2}$ and $\mathrm{O}_{2}^{-}$release from neutrophils of smokers and patients with chronic obstructive pulmonary diseases (COPD) (Nagy et al. 1997). An in vitro study demonstrated NAC inhibited TGF- $\beta 1$-induced profibrotic responses in fibroblasts (Sugiura et al. 2009). NAC was found to ameliorate bleomycin-induced pulmonary fibrosis in rats by inhibition of lysyl oxidase activity via elevation of lung GSH ( $\mathrm{Li}$ et al. 2012b). In our previous studies NAC has been found significantly increased total intracellular GSH in stretched rat lung (Syrkina et al. 2008) and inhibited collagen synthesis and GSH reduction induced by LPS in pulmonary fibroblasts (Li et al. 2011). In the present study, in vivo NAC $(140 \mathrm{mg} / \mathrm{kg})$ intervention alleviated the collagen accumulation included by high tidal-volume ventilation $(20 \mathrm{ml} / \mathrm{kg})$, in vitro NAC $(1 \mathrm{mM})$ decreased collagen content in culture medium included by cyclic cell stretch of NHLF. Since administration in present in vivo and in vitro study inhibited collagen accumulation, NAC may attenuate pulmonary fibroproliferation in this model.

In many patients, because of the severity of the underlying disease, it is impossible to provide a lung protective strategy for all lung units. A therapy that could modulate the fibrotic response could be beneficial. NAC could specifically minimize the pulmonary fibroproliferation associated with mechanical ventilation and hopefully lead to improved outcomes in patients with ARDS. More studies are needed to further investigate the dose, time and route of NAC.

The present study has some limitations. The exact underlying mechanism should be investigated in future, such as the detailed inflammatory cells, inflammatory cytokines and/or free radicals that are involved. Also, we would like to investigate the major type types of collagen that are responsible for our study. Furthermore our study focused on the collagen accumulation, not the ultimate pathological fibrosis, the role of mechanical ventilation in fibroproliferation to fibrosis need be clarified in future. More studies also need to investigate the dose and time of NAC administration as well as its potential functional in VILI restoration.

In summary, this study demonstrated that mechanical ventilation can induce collagen accumulation in early stages. This process partly depends on the time and magnitude of stretch. NAC, a thiol antioxidant alleviated the collagen accumulation included by high tidal-volume mechanical ventilation and may help in the development of prevention of lung fibrosis in ARDS patients who received mechanical ventilation.

\section{Acknowledgments}

The authors thank Yang Xia and Fengyang Lei for providing language help. This work was supported by the grant from the National Natural Science Foundation of China No. 81071536.

\section{Conflict of Interest}

The authors declare no conflict of interest.

\section{References}

Bridgeman, M.M., Marsden, M., Selby, C., Morrison, D. \& MacNee, W. (1994) Effect of N-acetyl cysteine on the concentrations of thiols in plasma, bronchoalveolar lavage fluid, and lung tissue. Thorax, 49, 670-675.

Burnham, E.L., Janssen, W.J., Riches, D.W., Moss, M. \& Downey, G.P. (2014) The fibroproliferative response in acute respiratory distress syndrome: mechanisms and clinical significance. Eur. Respir. J., 43, 276-285.

Cabrera-Benitez, N.E., Laffey, J.G., Parotto, M., Spieth, P.M., Villar, J., Zhang, H. \& Slutsky, A.S. (2014) Mechanical ventilation-associated lung fibrosis in acute respiratory distress syndrome: a significant contributor to poor outcome. Anesthesiology, 121, 189-198.

Cabrera-Benitez, N.E., Parotto, M., Post, M., Han, B., Spieth, P.M., Cheng, W.E., Valladares, F., Villar, J., Liu, M., Sato, M., Zhang, H. \& Slutsky, A.S. (2012) Mechanical stress induces lung fibrosis by epithelial-mesenchymal transition. Crit. Care Med., 40, 510-517.

Chapman, K.E., Sinclair, S.E., Zhuang, D., Hassid, A., Desai, L.P. \& Waters, C.M. (2005) Cyclic mechanical strain increases reactive oxygen species production in pulmonary epithelial cells. Am. J. Physiol. Lung Cell. Mol. Physiol., 289, L834841.

Chesnutt, A.N., Matthay, M.A., Tibayan, F.A. \& Clark, J.G. (1997) Early detection of type III procollagen peptide in acute lung injury. Pathogenetic and prognostic significance. Am. J. Respir. Crit. Care Med., 156, 840-845.

Choi, W.I., Quinn, D.A., Park, K.M., Moufarrej, R.K., Jafari, B., Syrkina, O., Bonventre, J.V. \& Hales, C.A. (2003) Systemic microvascular leak in an in vivo rat model of ventilatorinduced lung injury. Am. J. Respir. Crit. Care Med., 167, 1627-1632.

Davidovich, N., DiPaolo, B.C., Lawrence, G.G., Chhour, P., Yehya, N. \& Margulies, S.S. (2013) Cyclic stretch-induced oxidative stress increases pulmonary alveolar epithelial permeability. Am. J. Respir. Cell Mol. Biol., 49, 156-164.

Dunn, I. \& Pugin, J. (1999) Mechanical ventilation of various human lung cells in vitro: identification of the macrophage as the main producer of inflammatory mediators. Chest, 116, 95S-97S.

Garcia, C.S., Rocco, P.R., Facchinetti, L.D., Lassance, R.M., Caruso, P., Deheinzelin, D., Morales, M.M., Romero, P.V., Faffe, D.S. \& Zin, W.A. (2004) What increases type III procollagen mRNA levels in lung tissue: stress induced by changes in force or amplitude? Respir. Physiol. Neurobiol., 144, 59-70.

Ichikado, K., Muranaka, H., Gushima, Y., Kotani, T., Nader, H.M., Fujimoto, K., Johkoh, T., Iwamoto, N., Kawamura, K., Nagano, J., Fukuda, K., Hirata, N., Yoshinaga, T., Ichiyasu, H., Tsumura, S., et al. (2012) Fibroproliferative changes on highresolution $\mathrm{CT}$ in the acute respiratory distress syndrome predict mortality and ventilator dependency: a prospective observational cohort study. BMJ Open, 2, e000545.

Jafari, B., Ouyang, B., Li, L.F., Hales, C.A. \& Quinn, D.A. (2004) Intracellular glutathione in stretch-induced cytokine release from alveolar type-2 like cells. Respirology, 9, 43-53.

Karadag, F., Karul, A.B., Cildag, O., Altun, C. \& Gurgey, O. (2004) Determinants of BMI in patients with COPD. Respirology, 9, 70-75.

Li, L.F., Chu, P.H., Hung, C.Y., Kao, W.W., Lin, M.C., Liu, Y.Y. \& Yang, C.T. (2013) Lumican regulates ventilation-induced epithelial-mesenchymal transition through extracelluar signalregulated kinase pathway. Chest, $\mathbf{1 4 3}, 1252-1260$. 
Li, L.F., Kao, K.C., Yang, C.T., Huang, C.C. \& Liu, Y.Y. (2012a) Ethyl pyruvate reduces ventilation-induced neutrophil infiltration and oxidative stress. Exp. Biol. Med. (Maywood), 237, 720-727.

Li, X.F., Ouyang, B., Wu, J.F., Chen, J. \& Guan, X.D. (2011) $\mathrm{N}$-acetylcysteine (NAC) inhibited pulmonary fibrosis in acute respiratory distress syndrome (ARDS). Zhongguo Wei Zhong Bing Ji Jiu Yi Xue, 23, 599-601.

Li, S., Yang, X., Li, W., Li, J., Su, X., Chen, L. \& Yan, G. (2012b) $\mathrm{N}$-acetylcysteine downregulation of lysyl oxidase activity alleviating bleomycin-induced pulmonary fibrosis in rats. Respiration, 84, 509-517.

Lopez, E., del Pozo, V., Miguel, T., Sastre, B., Seoane, C., Civantos, E., Llanes, E., Baeza, M.L., Palomino, P., Cardaba, B., Gallardo, S., Manzarbeitia, F., Zubeldia, J.M. \& Lahoz, C. (2006) Inhibition of chronic airway inflammation and remodeling by galectin-3 gene therapy in a murine model. $J$. Immunol., 176, 1943-1950.

Marshall, R.P., Bellingan, G., Webb, S., Puddicombe, A., Goldsack, N., McAnulty, R.J. \& Laurent, G.J. (2000) Fibroproliferation occurs early in the acute respiratory distress syndrome and impacts on outcome. Am. J. Respir. Crit. Care Med., 162, 1783-1788.

Martin, C., Papazian, L., Payan, M.J., Saux, P. \& Gouin, F. (1995) Pulmonary fibrosis correlates with outcome in adult respiratory distress syndrome. A study in mechanically ventilated patients. Chest, 107, 196-200.

Mascarenhas, M.M., Day, R.M., Ochoa, C.D., Choi, W.I., Yu, L., Ouyang, B., Garg, H.G., Hales, C.A. \& Quinn, D.A. (2004) Low molecular weight hyaluronan from stretched lung enhances interleukin-8 expression. Am. J. Respir. Cell Mol. Biol., 30, 51-60.

Nagy, A.M., Vanderbist, F., Parij, N., Maes, P., Fondu, P. \& Neve, J. (1997) Effect of the mucoactive drug nacystelyn on the respiratory burst of human blood polymorphonuclear neutrophils. Pulm. Pharmacol. Ther., 10, 287-292.

Papazian, L., Doddoli, C., Chetaille, B., Gernez, Y., Thirion, X., Roch, A., Donati, Y., Bonnety, M., Zandotti, C. \& Thomas, P. (2007) A contributive result of open-lung biopsy improves survival in acute respiratory distress syndrome patients. Crit. Care Med., 35, 755-762.

Park, H.S., Kim, S.R. \& Lee, Y.C. (2009) Impact of oxidative stress on lung diseases. Respirology, 14, 27-38.

Parker, J.C., Breen, E.C. \& West, J.B. (1997) High vascular and airway pressures increase interstitial protein mRNA expression in isolated rat lungs. J. Appl. Physiol. (1985), 83, 16971705 .

Pires, K.M., Melo, A.C., Lanzetti, M., Casquilho, N.V., Zin, W.A., Porto, L.C. \& Valenca, S.S. (2012) Low tidal volume mechanical ventilation and oxidative stress in healthy mouse lungs. $J$. Bras. Pneumol., 38, 98-104.

Quinn, D.A., Moufarrej, R.K., Volokhov, A. \& Hales, C.A. (2002) Interactions of lung stretch, hyperoxia, and MIP-2 production in ventilator-induced lung injury. J. Appl. Physiol. (1985), 93, 517-525.

Raghu, G., Collard, H.R., Egan, J.J., Martinez, F.J., Behr, J., Brown, K.K., Colby, T.V., Cordier, J.F., Flaherty, K.R., Lasky, J.A., Lynch, D.A., Ryu, J.H., Swigris, J.J., Wells, A.U., Ancochea, J., et al. (2011) An official ATS/ERS/JRS/ALAT statement: idiopathic pulmonary fibrosis: evidence-based guidelines for diagnosis and management. Am. J. Respir. Crit. Care Med., 183, 788-824.

Slutsky, A.S. \& Ranieri, V.M. (2013) Ventilator-induced lung injury. N. Engl. J. Med., 369, 2126-2136.

Sugiura, H., Ichikawa, T., Liu, X., Kobayashi, T., Wang, X.Q., Kawasaki, S., Togo, S., Kamio, K., Mao, L., Ann, Y., Ichinose, M. \& Rennard, S.I. (2009) N-acetyl-L-cysteine inhibits TGF-beta1-induced profibrotic responses in fibroblasts. Pulm. Pharmacol. Ther, 22, 487-491.

Suki, B., Ito, S., Stamenovic, D., Lutchen, K.R. \& Ingenito, E.P. (2005) Biomechanics of the lung parenchyma: critical roles of collagen and mechanical forces. J. Appl. Physiol. (1985), 98, 1892-1899.

Syrkina, O., Jafari, B., Hales, C.A. \& Quinn, D.A. (2008) Oxidant stress mediates inflammation and apoptosis in ventilatorinduced lung injury. Respirology, 13, 333-340.

Tatler, A.L. \& Jenkins, G. (2012) TGF-beta activation and lung fibrosis. Proc. Am. Thorac. Soc., 9, 130-136.

Villar, J., Cabrera, N.E., Valladares, F., Casula, M., Flores, C., Blanch, L., Quilez, M.E., Santana-Rodriguez, N., Kacmarek, R.M. \& Slutsky, A.S. (2011) Activation of the Wnt/betacatenin signaling pathway by mechanical ventilation is associated with ventilator-induced pulmonary fibrosis in healthy lungs. PLoS One, 6, e23914. 